\title{
VELOCITY EXPONENT AND CAVITATION NUMBER FOR VENTURI CAVITATION EROSION OF 1100-O ALUMINUM AND 1018 CARBON STEEL
}

\author{
JU-GEN HE* and F. G. HAMMITT
}

Department of Mechanical Engineering and Applied Mechanics, Cavitation and Multiphase Flow Laboratory, University of Michigan, Ann Arbor, MI 48109 (U.S.A.)

(Received November 11,1981 ; in revised form December 7,1981 )

\section{Summary}

The purpose of the present investigation is to evaluate the effect of Venturi throat velocity on the cavitation erosion of specimens for constant cavitation number, which is here based on Venturi discharge conditions. 1018 carbon steel and 1100-O aluminum were tested in the University of Michigan high speed cavitation tunnel with tap water at $27{ }^{\circ} \mathrm{C}\left(80^{\circ} \mathrm{F}\right)$. Results of present tests are consistent with previous work done at the University of Michigan, showing that the velocity-damage exponent varies over the range $\pm 1-5$ for the velocity range $10-49 \mathrm{~m} \mathrm{~s}^{-1}$.

\section{Introduction}

Cavitation erosion is a major problem in liquid flow systems. Over many years, there have been many investigations of cavitation damage in hydrodynamic machinery both in laboratory and in field tests; investigations have attempted to find damage-predicting criteria for design and industrial applications. The most prominent and well-known cavitation damage "scale effects" are probably those due to variations in the velocity or suppression pressure [1]. Since in the conventional static vibratory facility, which is the most economical and accelerated device for cavitation erosion testing, basic flow parameters such as velocity are lacking, the velocity effect on damage can be investigated only in flow systems such as a Venturi system. However, in such systems more time is needed to attain results and they are therefore more expensive.

The now well-known velocity effect "exponent law" (the damage rate is proportional to $V^{n}$ ) was first proposed by Knapp [2]. He investigated velocity effects on the pitting rates of soft aluminum in a water tunnel at the California Institute of Technology in the 1950s. He found that the

*Visiting Scholar from the National Academy of Space Technology, Beijing, China. 
exponent was about 6 . Because of its simplicity, Knapp's exponent law has been widely adopted in the comparison of velocity damage data. However, the model appears to be oversimplified. Values of the velocity exponent reported elsewhere (e.g. refs. 1 and 3 ) vary over a very wide range from about - 74 to 17. Most investigators [4], however, have obtained exponents closer to the exponent found by Knapp. Previous data summarized in Table 1 (which is from ref. 4) are included here for convenience. The large scatter of velocity exponent values indicates that it is affected by numerous factors such as suppression pressure, cavitation number $\sigma(\sigma$ is defined in eqn. (1)), the geometry of the flow device, the Reynolds number, the size and shape of the cavitation source, test fluid (e.g. the air content in water), flow stability, the material and shape of the specimens etc.

It is obvious that velocity and suppression pressure cannot be varied arbitrarily and independently if the cavitation number $\sigma$ is to be maintained constant. It is considered probable that the erosion exponent $n$ will be very sensitive to variation in downstream suppression pressure. The cavitation number is thus here so defined. Also, "pseudo" and "true" damage scale effects [1] should be distinguished. True damage scale effects are defined [1] as those for which the cavitation number and the flow geometry are fixed.

Venturi damage tests at constant $\sigma$ for two materials (1018 carbon steel and 1100-O aluminum) were recently conducted in the high speed cavitation tunnel at the University of Michigan in tap water at $27^{\circ} \mathrm{C}\left(80^{\circ} \mathrm{F}\right)$. The purpose of these tests was to study and evaluate the effect of flow velocity on cavitation erosion and to compare the results with previous data from the same facility.

\section{Venturi tunnel}

The cavitation tests were performed in a high speed closed-loop cavitation tunnel. The Venturi Plexiglas test section is shown in Fig. 1. The throat diameter is $12.7 \mathrm{~mm}(0.510 \mathrm{in})$. The throat velocities, controlled by the pump speed and the downstream pressure (which is maintained by a surge tank attached to the downstream tank), were 36.3 and $49 \mathrm{~m} \mathrm{~s}^{-1}$. The water temperature was $27{ }^{\circ} \mathrm{C}\left(80^{\circ} \mathrm{F}\right)$. Two erosion specimens $(6.35 \mathrm{~mm}$ in diameter) were inserted flush with the Venturi diffuser wall in the same axial plane (Fig. 1) together with a pressure probe (for some tests). Termination of the cavitation cloud (observed visually) is in the specimen-probe plane for the lower velocity. It moves somewhat upstream for the higher velocity, if $\sigma$ is maintained constant.

The cavitation number $K$ (also symbolized by $\sigma$ ) is defined for these tests as follows:

$$
\sigma=K=\frac{P_{\mathrm{d}}-P_{\mathrm{v}}}{0.5 \rho V^{2}}
$$




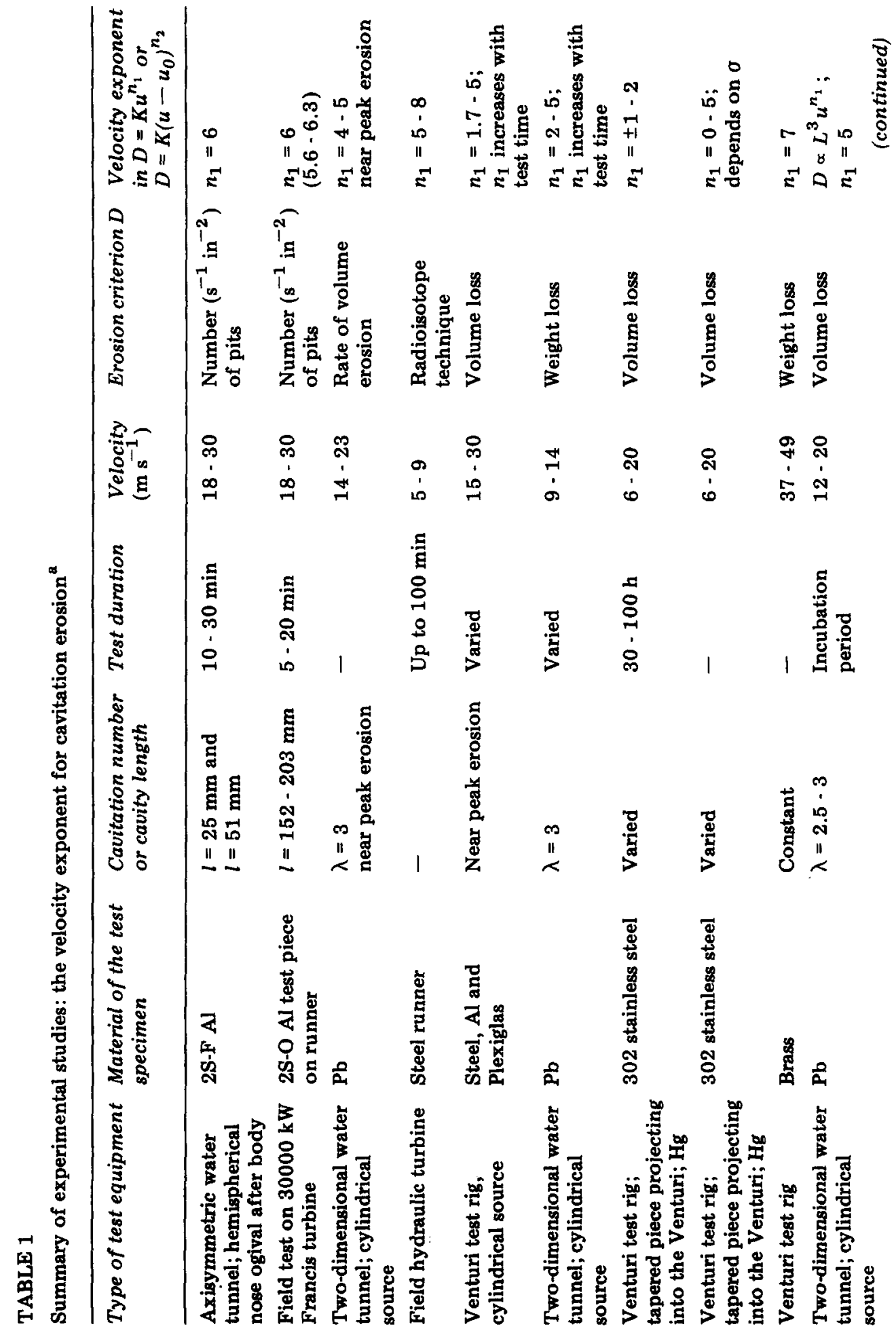




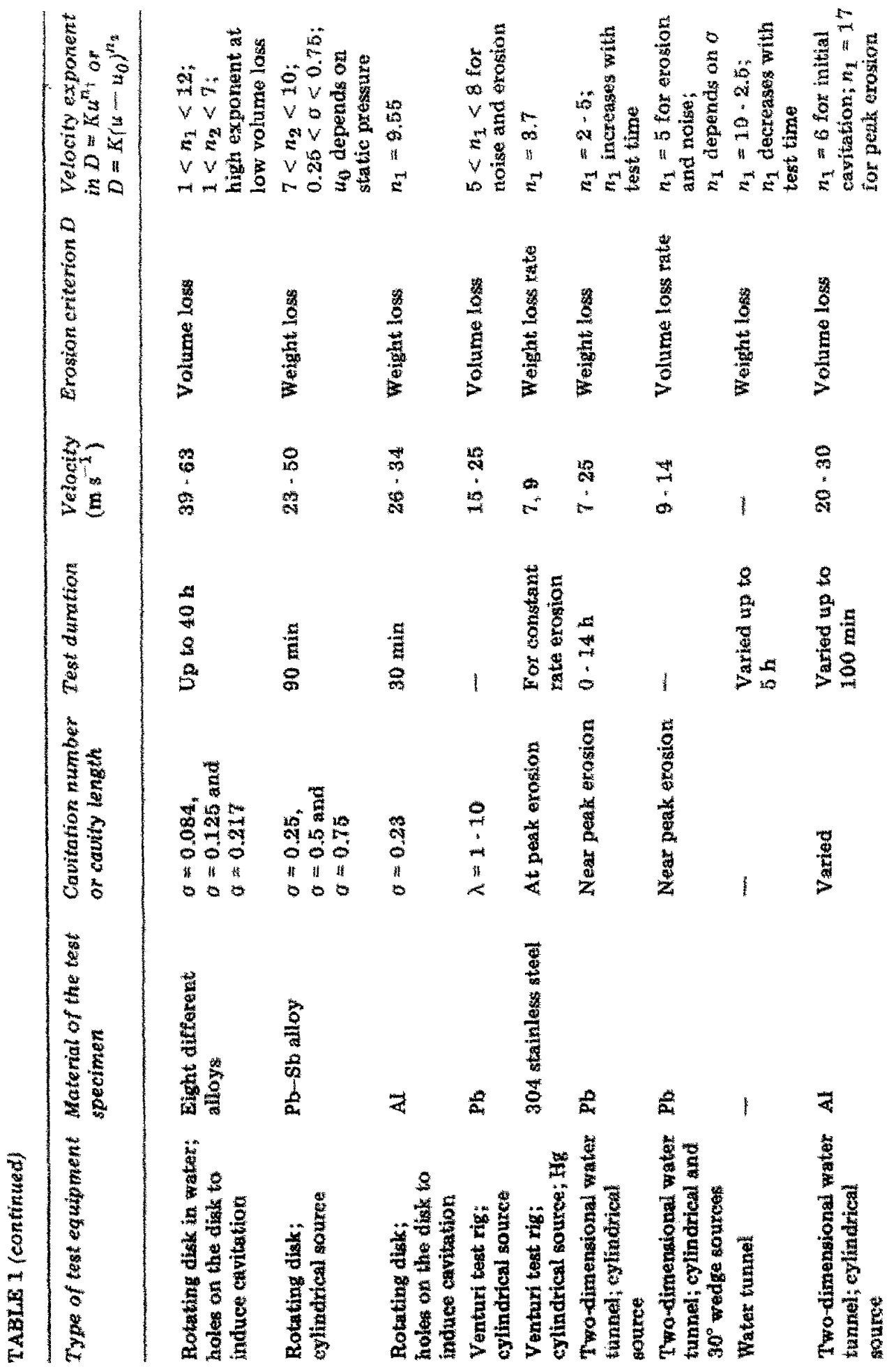




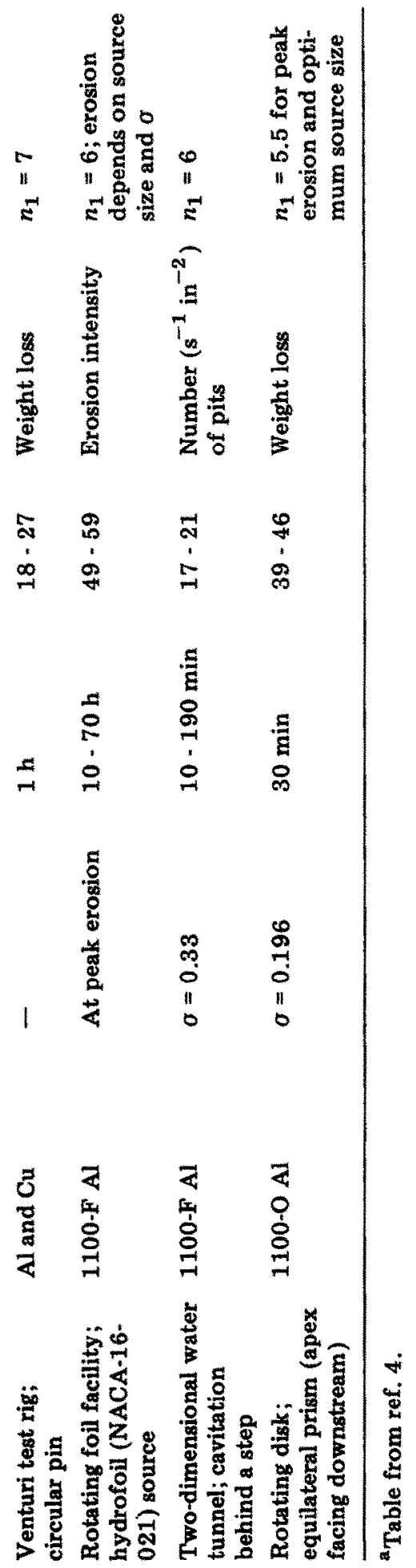



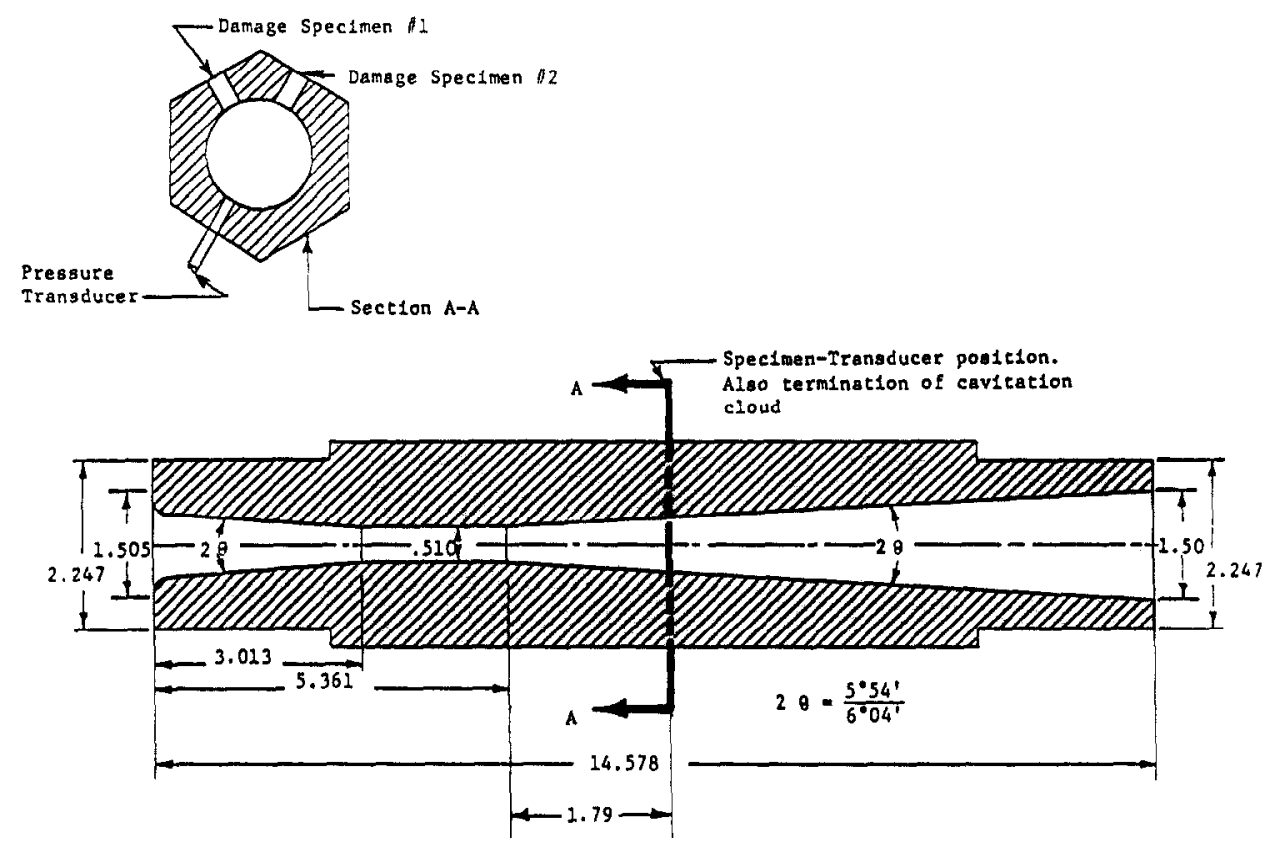

Fig. 1. Damage Venturi flow path (all dimensions in inches).

where $P_{\mathrm{d}}$ is the pressure immediately downstream of the Venturi, $P_{\mathrm{v}}$ the vapor pressure, $V$ the throat velocity and $\rho$ the liquid density. Since the cavitation damage rate has been shown here to be very sensitive to downstream pressure, this value is used to define the cavitation number $\sigma$.

In the Venturi tunnel at the University of Michigan, the cavitation condition and throat velocity are controlled by the pump speed and the visual observation of the termination of the cavitation cloud. It is desirable to terminate this cloud approximately in the axial plane where the specimens are located. This setting can be achieved by regulating both upstream and downstream pressures to hold the pressure difference across the Venturi section as needed to obtain the desired throat velocity for the proper termination point. For given Venturi and cavitation cloud termination, there should ideally be only one cavitation number for a given throat velocity. However, bubbles in the cavitation cloud cover an extended axial region in the Venturi (Fig. 2) and do not collapse in a simple steady state plane, as earlier confirmed by high speed motion pictures [1]. For this reason, and also because of other undefined cavitation scale effects, different values for $\sigma$ were obtained when the throat velocity was varied and the visual cavitation termination point was held constant. Thus the cavitation number was maintained constant for the present tests although the visual termination point then varied, moving slightly upstream as the velocity was increased. 


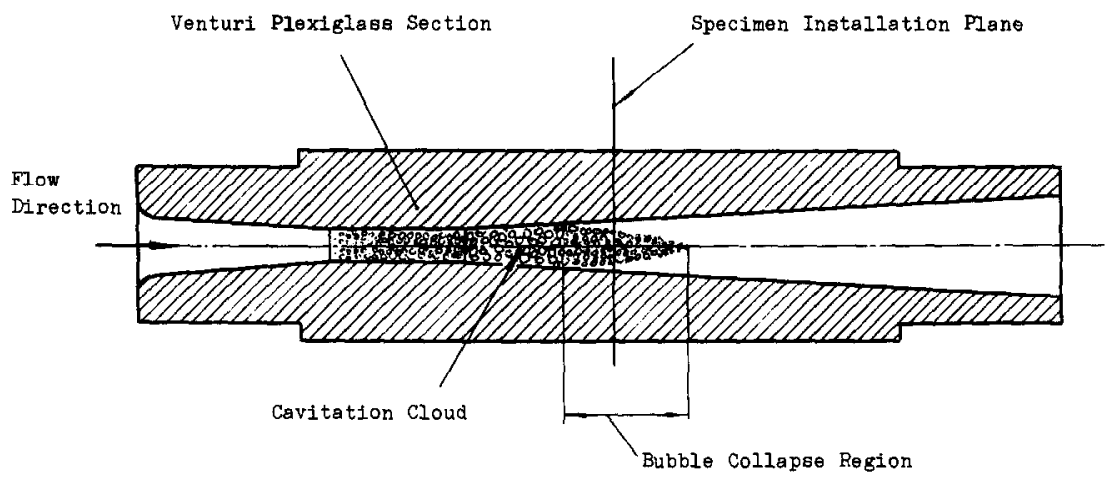

Fig. 2. Cavitation cloud in Venturi test section.

\section{Test results}

Figure 3 shows the cumulative erosion of 1018 carbon steel specimens as a function of cumulative time. The results are summarized in Table 2. Curves 1 and 2 of Fig. 3 allow a constant $\sigma(0.76)$ comparison. Values of the mean depth of penetration rate MDPR are the best straight line approximations for the steady portion of the cumulative curves. They are thus not maximum values $M D P R_{\max }$. In these and other curves the small oscillations in the erosion rate should be noted. These variations are valid, since they generally involve several successive data points. A comparison of curves 1 and 2 of Fig. 3 shows that the velocity exponent $n$ in the relation MDPR $\propto$ $V^{n}$ is 1.06 at $\sigma=0.76$ (see Fig. 8). Thus velocity in this test did not have as much effect on the erosion rate as usual. Figure 3, curves 1 and 3 , are for the same velocity, but differing values of $\sigma$. The erosion rate from Fig. 3 , curve 1 (higher $\sigma$ ), is four times higher than that from Fig. 3, curve 3, which is for a lower (0.62) value of $\sigma$.

\section{TABLE 2}

Summary of results for 1018 carbon steel

\begin{tabular}{llllll}
\hline Specimen number & $\begin{array}{l}\text { Throat velocity } \\
\left(\mathrm{m} \mathrm{s}^{-1}\right)\end{array}$ & $\begin{array}{l}\text { Cavitation } \\
\text { number } K\end{array}$ & $\begin{array}{l}\text { MDPR } \\
\left(\mu \mathrm{m} \mathrm{h}^{-1}\right.\end{array}$ & $\left.\left(\times 10^{-3} \mathrm{in} \mathrm{h}^{-1}\right)\right)$ & $n^{\mathrm{a}}$ \\
\hline $16, \mathrm{Cr}-5, \mathrm{Cr}-4$ & 49 & 0.76 & 1.12 & $(0.044)$ & 1.06 \\
$11,12^{\mathrm{b}}$ & 36.3 & 0.76 & 0.81 & $(0.032)$ & \\
$7,8^{\mathrm{b}}$ & 49 & 0.62 & 0.31 & $(0.012)$ & \\
\hline
\end{tabular}

${ }^{a} n$ is the exponent in the relation MDPR $\propto V^{n} ; K=0.76$.

${ }^{b}$ Reference 5 . 


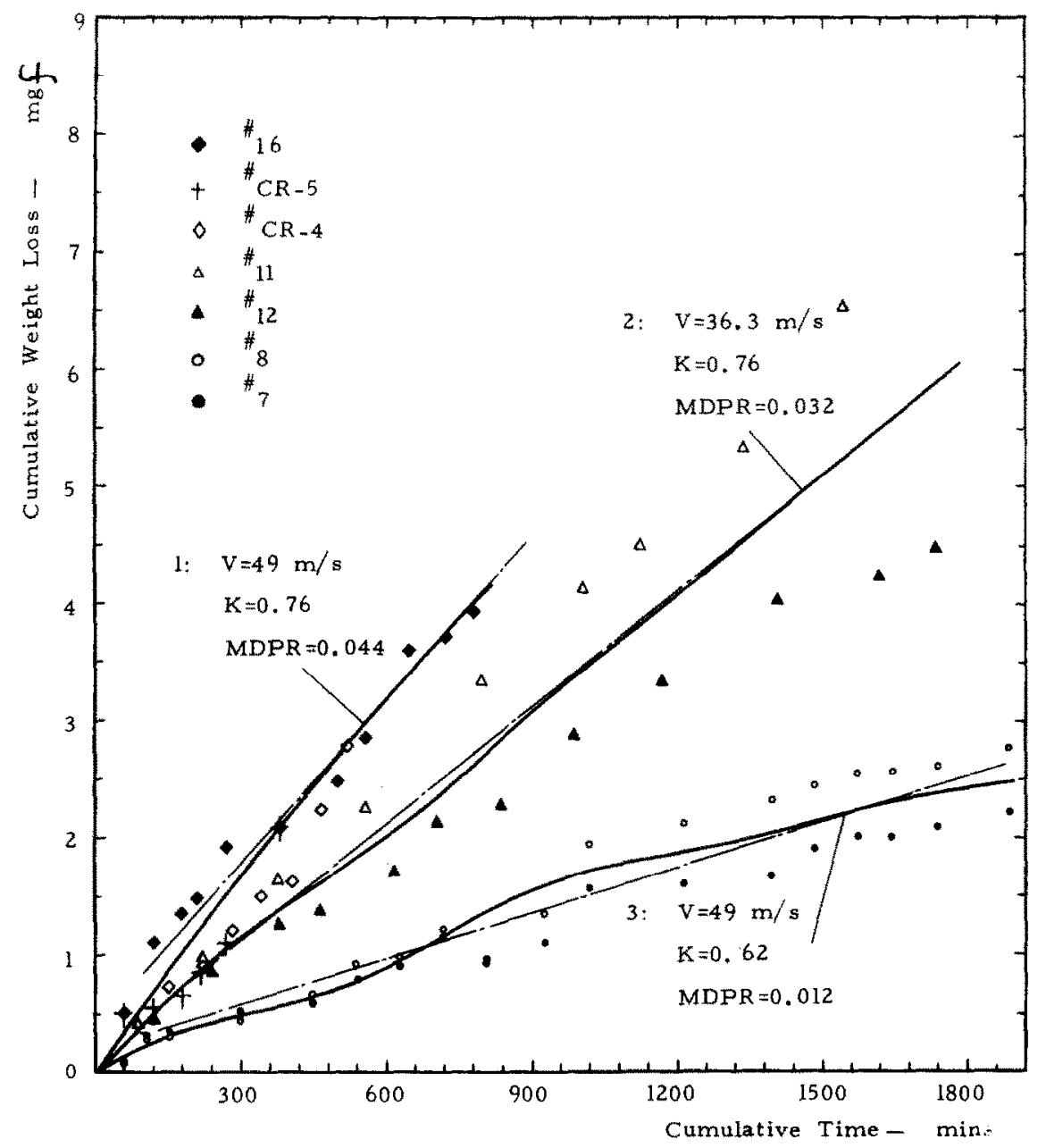

Fig. 3. Effect of $\sigma$ and velocity in 1018 carbon steel Venturi test in tap water at $80^{\circ} \mathrm{F}$.

Figure 4 shows the probable overall variation in MDPR with $\sigma$ for these tests for both aluminum and carbon steel. The MDPR variation for changing $\sigma$ is presumably caused by the conflicting effects at increasing suppression pressure $P_{\mathrm{gv}}=P_{\mathrm{d}}-P_{\mathrm{v}}$ of increased stresses from bubble collapse and the reduced number of bubbles. Damage of course vanishes at either very high values of $\sigma$ (no cavitation) or very low values of $\sigma\left(P_{\mathrm{sv}}=0\right)$. Since the erosion rate increases strongly with $\sigma$, at least for carbon steel, over the velocity range tested, it is certain that a simple velocity exponent model is not in general tenable.

Figures $5-7$ show the results of various tests of weight loss versus cumulative time for 1100-0 aluminum. These are summarized in Table 3. Figure 5, which shows our latest results, agrees fairly well with our previous 


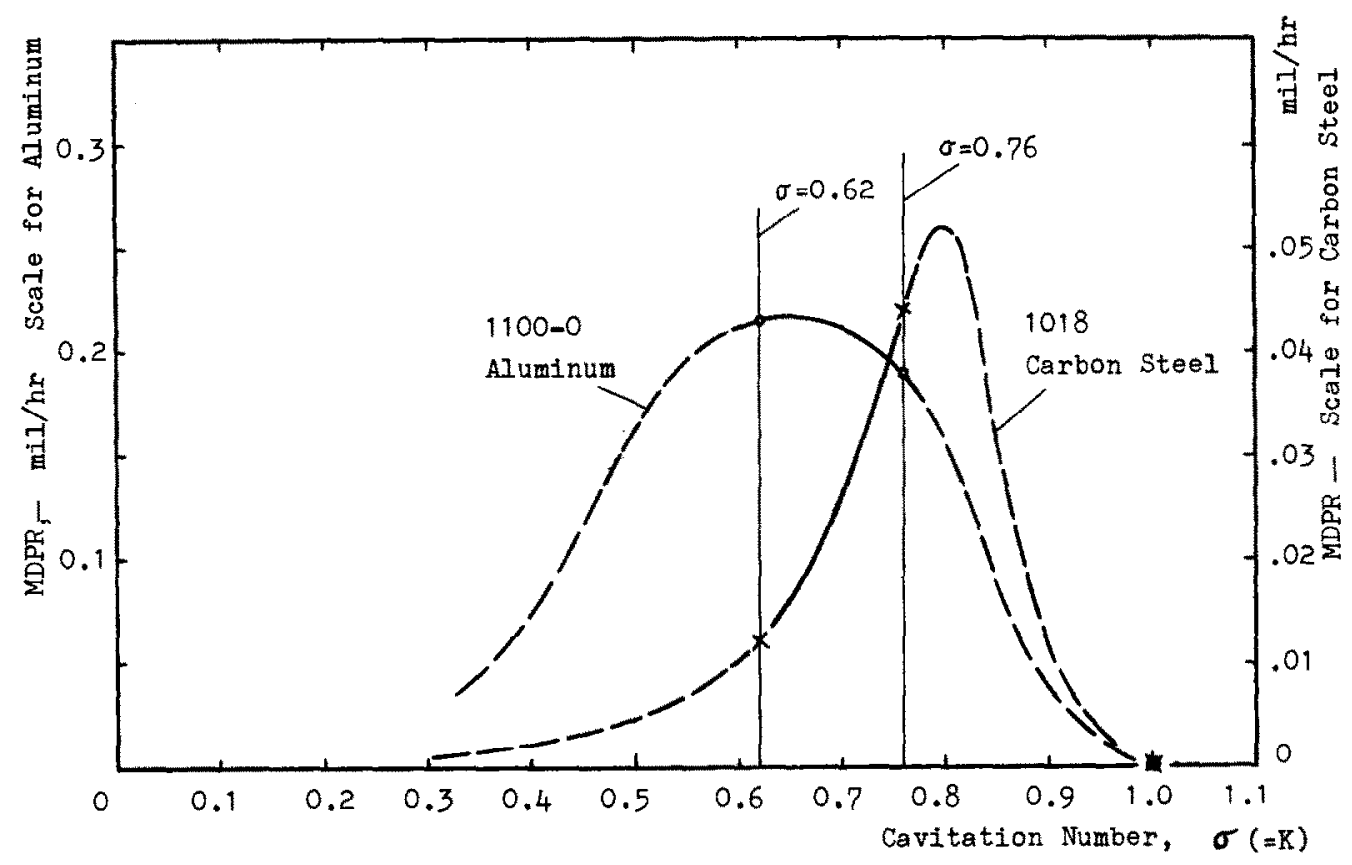

Fig. 4. Effect of the downstream cavitation number on the erosion rate in the University of Michigan Venturi at a velocity of $49 \mathrm{~m} \mathrm{~s}^{-1}$.

TABLE 3

Summary of results for $1100-0$ aluminum

\begin{tabular}{|c|c|c|c|c|c|}
\hline Specimen number & $\begin{array}{l}\text { Throat velocity } \\
\left(\mathrm{m} \mathrm{s}^{-1}\right)\end{array}$ & $\begin{array}{l}\text { Cavitation } \\
\text { number } K\end{array}$ & $\begin{array}{l}\text { MDPR } \\
\left(\mu \mathrm{m} \mathrm{h}^{-}\right.\end{array}$ & $\left(\times 10^{-3}\right.$ in h $\left.\left.^{-1}\right)\right)$ & $n^{a}$ \\
\hline $\begin{array}{l}3,4^{\mathrm{b}} \\
1,2^{\mathrm{c}}\end{array}$ & $\begin{array}{l}49 \\
49\end{array}$ & $\begin{array}{l}0.76 \\
0.76\end{array}$ & $\begin{array}{l}6.35 \\
3.30\end{array}$ & $\begin{array}{l}(0.25) \\
(0.13)\end{array}$ & \\
\hline $\begin{array}{l}4 \\
3^{d} \\
\text { Plain } 1^{e} \\
\text { Plain } 2^{e} \\
\text { Curve 1 } \\
\text { Curve } 2^{\mathrm{e}} \\
\text { Plain 1 } \\
\text { Plain } 2^{\mathrm{e}} \\
\text { Curve 1 } \\
\text { Curve 2 }^{\mathrm{e}}\end{array}$ & $\begin{array}{l}49 \\
49 \\
49 \\
49 \\
49 \\
49 \\
36.3 \\
36.3 \\
36.3 \\
36.3\end{array}$ & $\begin{array}{l}0.62 \\
0.62 \\
0.61 \\
0.61 \\
0.61 \\
0.61 \\
0.56 \\
0.56 \\
0.56 \\
0.56\end{array}$ & $\begin{array}{l}6.35 \\
4.47 \\
7.07 \\
7.19 \\
4.72 \\
6.93 \\
1.83 \\
1.96 \\
1.77 \\
1.78\end{array}$ & $\begin{array}{l}(0.25) \\
(0.18) \\
(0.28) \\
(0.28) \\
(0.19) \\
(0.27) \\
(0.072) \\
(0.077) \\
(0.070) \\
(0.071)\end{array}$ & $4.0_{-31 \%}^{+16 \%}$ \\
\hline
\end{tabular}

${ }^{a} n$ is the exponent in the relation MDPR $\propto V^{n} ; K=0.60$.

${ }^{b}$ Reference 6 .

${ }^{c}$ Reference 7 .

dReference 8 .

Reference 9 . 


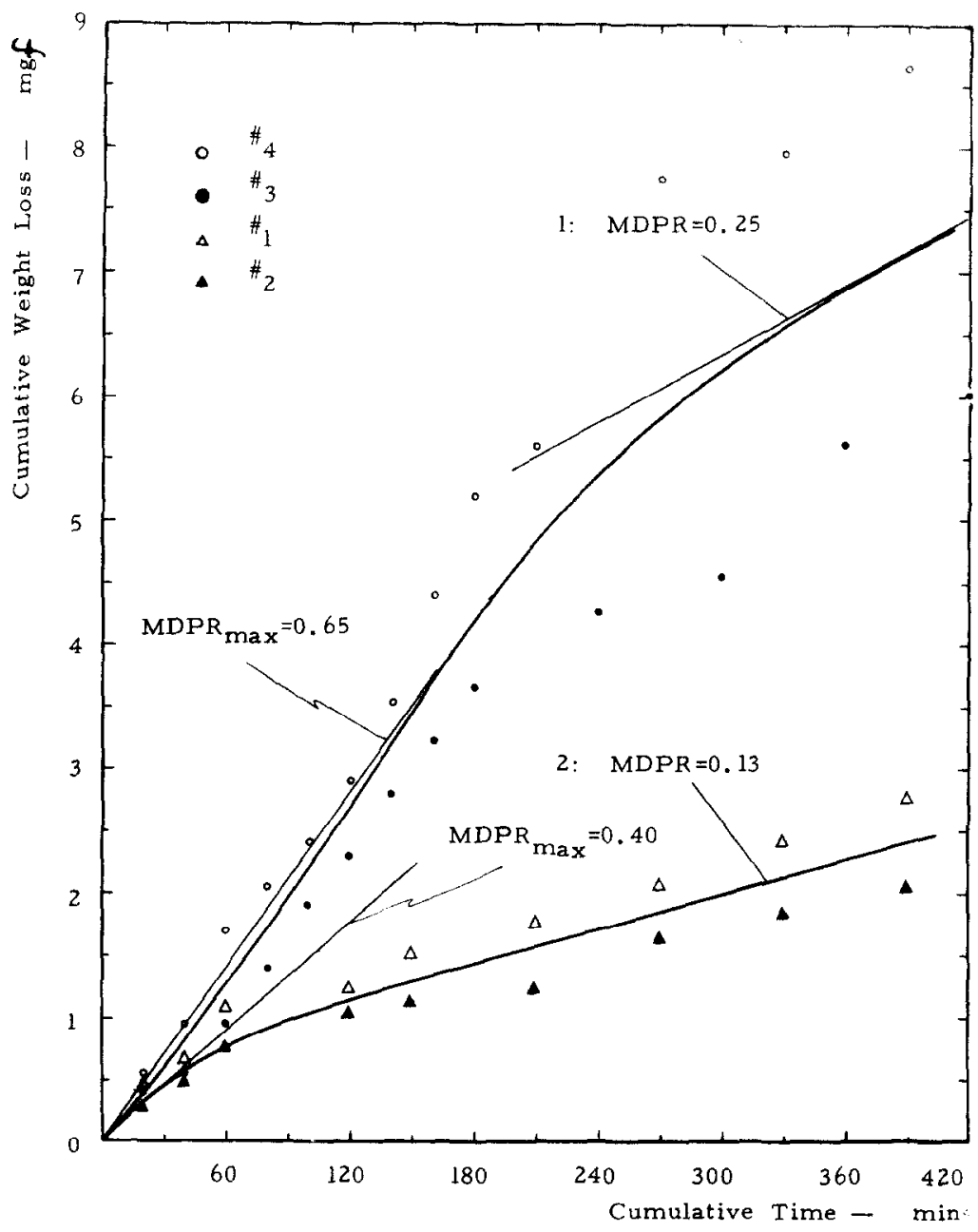

Fig. 5. Weight loss $v 8$. cumulative time for $1100-0$ aluminum Venturi tests (tap water at $80^{\circ} \mathrm{F}$; velocity, $49 \mathrm{~m} \mathrm{~s}^{-1} ; K=0.76$ ).

data $[5,10,11]$. These had shown a velocity exponent $n \approx 4$ (Fig. 7 ) in the relation MDPR $\propto V^{n}$. In these tests with a fixed cavitation termination point, $\sigma$ varied substantially, being equal to 0.56 for a velocity of $36.3 \mathrm{~m} \mathrm{~s}^{-1}$ and 0.61 for a velocity of $49 \mathrm{~m} \mathrm{~s}^{-1}$. Thus the velocity exponents are not valid for comparisons with constant $\sigma$. The same specimens (Fig. 7) were continued through the entire test for both velocities. It was thought [5] that the "preconditioning" from the low velocity portion of the tests might have affected the high velocity results. Hence, the high velocity test was repeated [8] and $n=3.5$ is obtained by a comparison between Figs. 6 and 7 . For the later tests (Fig. 6), the cavitation number was about 0.62 . The tests of Figs. 6 and 7 show that the preconditioning was in fact not very important. 


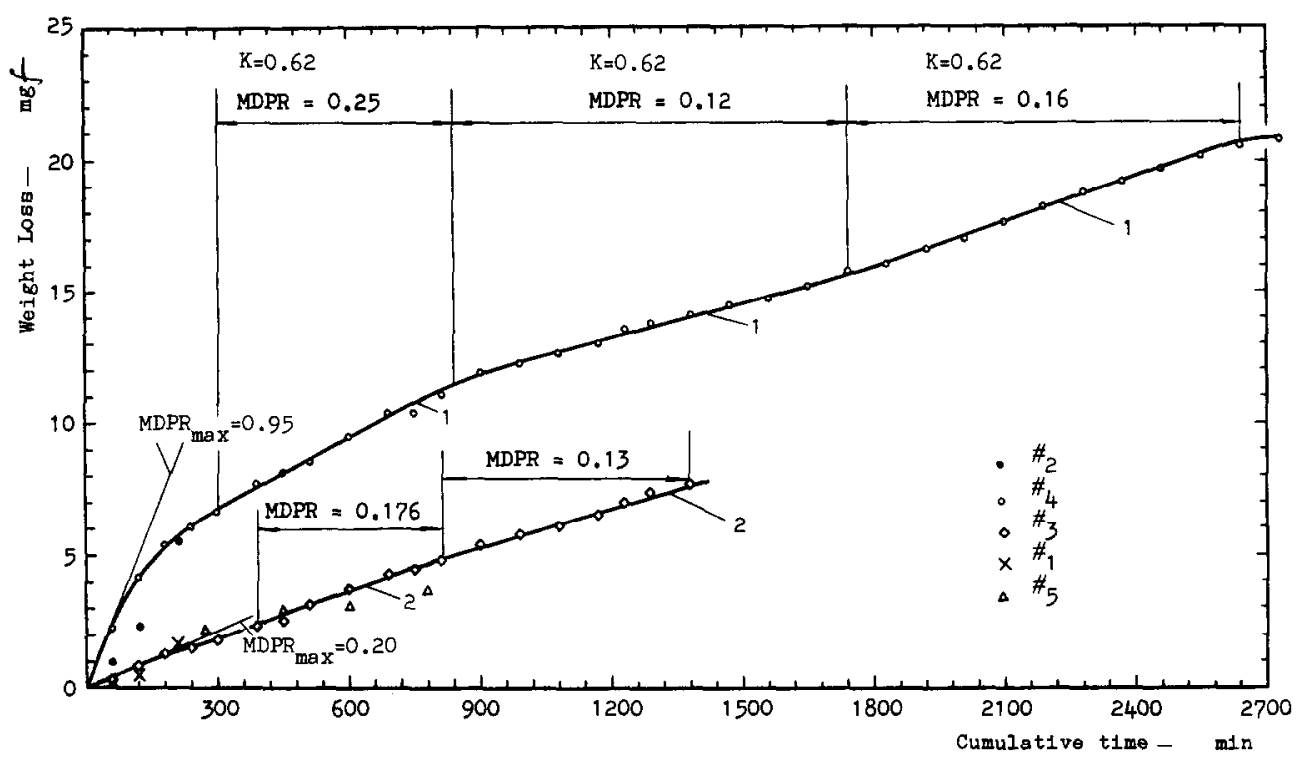

Fig. 6. Weight loss us. cumulative time for $1100-0$ aluminum Venturi cavitation erosion test (throat velocity, $49 \mathrm{~m} \mathrm{~s}^{-1}$ ).

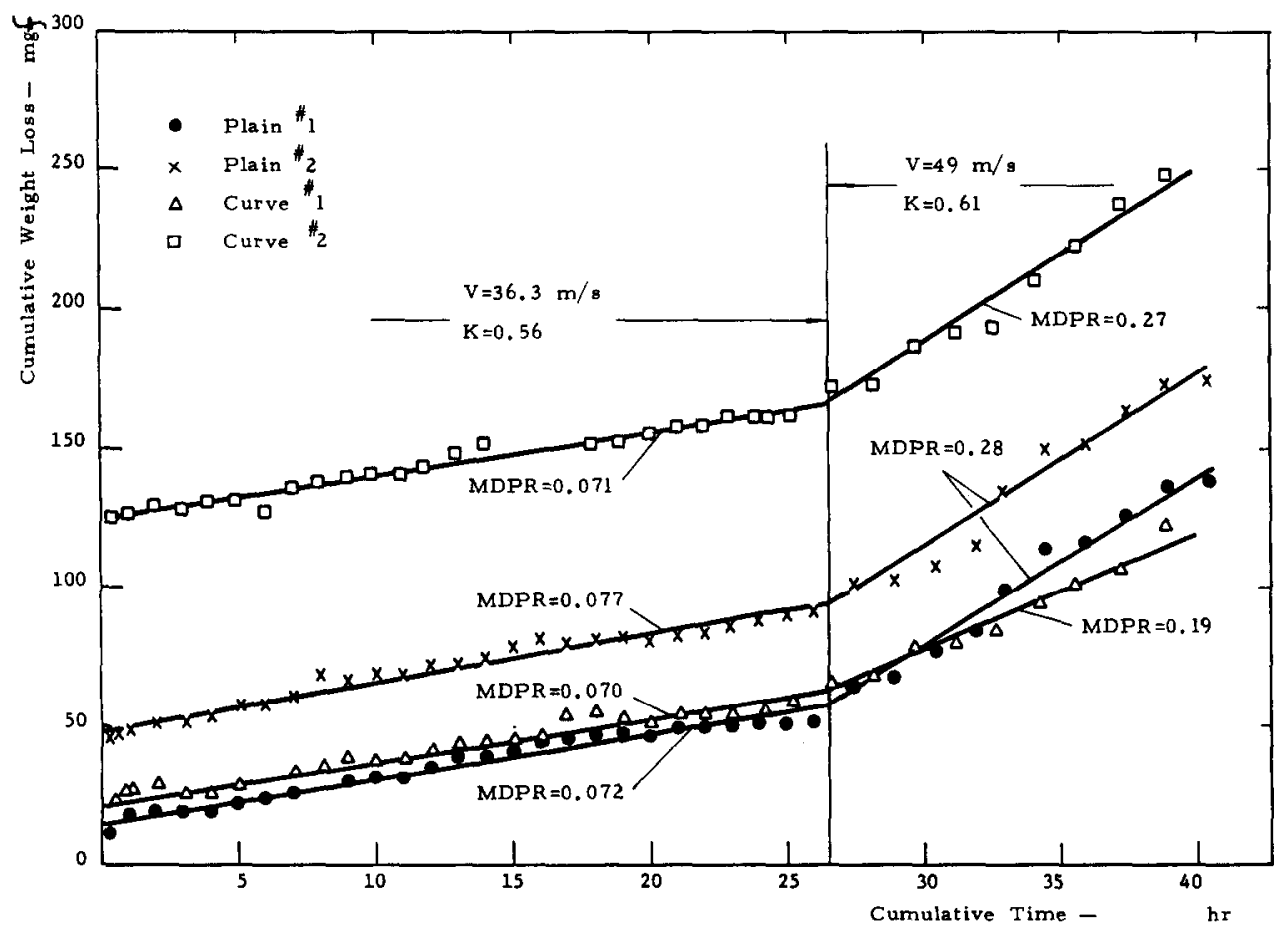

Fig. 7. Results of $1100-0$ aluminum Venturi cavitation damage tests in tap water at $80^{\circ} \mathrm{F}$. 
If all 1100-O aluminum data are combined on a log-log plot, a velocity exponent of about 4 is still obtained (Fig. 8) for 1100-O aluminum. However, for 1018 carbon steel, $n \approx 1.1$. The variation in $\sigma$ renders the exponent values inapplicable for constant $\sigma$ but pertinent to a constant extent of cavitation. For 1100-O aluminum the erosion rate (Table 3 and Fig. 4) does not vary appreciably with $\sigma$ for the two points tested. This result is consistent with our general $\sigma$-damage rate curves (Fig. 4).

All the velocity exponent data for cavitation erosion tests in the University of Michigan Venturi facility with water and also mercury as test liquids are summarized in Table 4 . In all cases, the exponents were less than

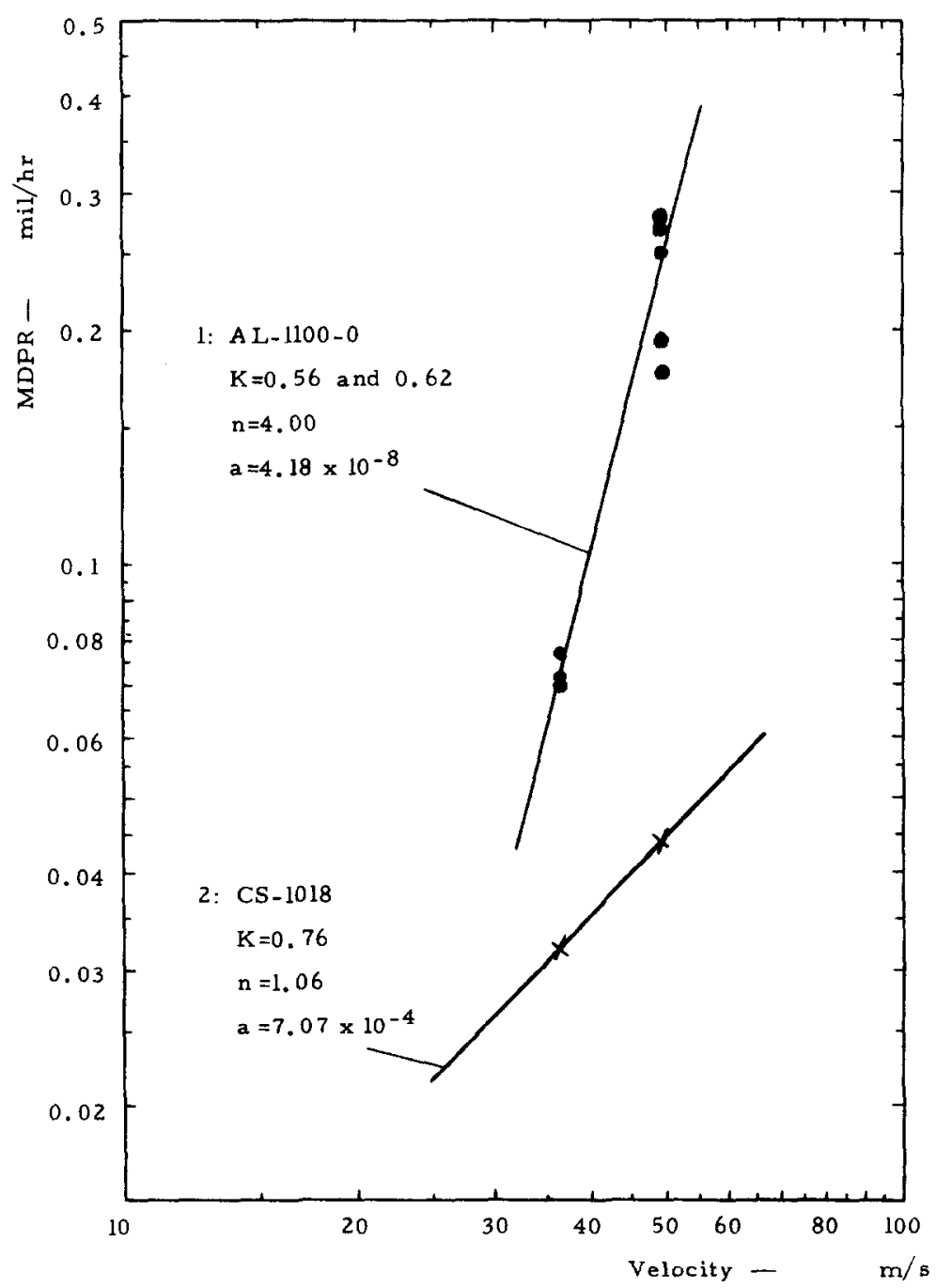

Fig. 8. Velocity exponent for Venturi cavitation erosion tests in tap water at $80^{\circ} \mathrm{F}$ : values of $a$ and $n$ are for the relation $M D P R=a V^{n}$. 
TABLE 4

Summary of velocity-damage exponent values for cavitation erosion tests at the University of Michigan

\begin{tabular}{|c|c|c|c|c|c|c|}
\hline $\begin{array}{l}\text { Type of test } \\
\text { equipment and } \\
\text { reference }\end{array}$ & $\begin{array}{l}\text { Test } \\
\text { fluids }\end{array}$ & $\begin{array}{l}\text { Materials } \\
\text { (test speci- } \\
\text { men) }\end{array}$ & $\begin{array}{l}\text { Cavitation } \\
\text { number } K\end{array}$ & $\begin{array}{l}\text { Test } \\
\text { duration } \\
(\mathrm{h})^{\mathrm{a}}\end{array}$ & $\begin{array}{l}\text { Velocity } \\
\left(\mathrm{m} \mathrm{s}^{-1}\right)\end{array}$ & $\begin{array}{l}\text { Velocity } \\
\text { exponent } n\end{array}$ \\
\hline $\begin{array}{l}\text { Venturi; cylindrical } \\
\text { throat; foil } \\
\text { specimen [12] }\end{array}$ & Water & $\begin{array}{l}\text { Stainless } \\
\text { steel } \\
\text { Carbon steel } \\
\text { Al }\end{array}$ & $\begin{array}{l}\text { Near peak } \\
\text { erosion }\end{array}$ & $\begin{array}{l}12 \\
3.5 \\
1 \\
5 \mathrm{~min}\end{array}$ & $10.4-20$ & $\begin{array}{l}4.9 \\
3.9 \\
2.4 \\
1.7\end{array}$ \\
\hline $\begin{array}{l}\text { Venturi; cylindrical } \\
\text { throat; foil } \\
\text { specimen [13] }\end{array}$ & $\mathrm{Hg}$ & $\begin{array}{l}302 \text { stainless } \\
\text { steel }\end{array}$ & Varied & $30 \cdot 100$ & $6 \cdot 20$ & $\pm 1 \cdot 2$ \\
\hline $\begin{array}{l}\text { Venturi; cylindrical } \\
\text { throat; foil } \\
\text { specimen [14] }\end{array}$ & $\mathrm{Hg}$ & $\begin{array}{l}302 \text { stainless } \\
\text { steel }\end{array}$ & Varied & $30-100$ & $6-20$ & $0-5$ \\
\hline $\begin{array}{l}\text { Venturi; cylindrical } \\
\text { throat; foil } \\
\text { specimen [15] }\end{array}$ & $\mathrm{Hg}$ & $\begin{array}{l}304 \text { stainless } \\
\text { steel }\end{array}$ & $\begin{array}{l}\text { At peak } \\
\text { erosion }\end{array}$ & $\begin{array}{l}\text { For con- } \\
\text { stant rate } \\
\text { erosion }\end{array}$ & 7,9 & 3.7 \\
\hline $\begin{array}{l}\text { Venturi shown in } \\
\text { Fig. } 1 \text { [8] }\end{array}$ & Water & $1100-0 \mathrm{Al}$ & $0.56-0.62$ & $20-45$ & $36.3 \cdot 49$ & $3.46 \pm 20 \%$ \\
\hline $\begin{array}{l}\text { Venturi shown in } \\
\text { Fig. } 1[6]\end{array}$ & Water & $1100-\mathrm{O} \mathrm{Al}$ & $0.56 \cdot 0.61$ & 40 & $36.3 \cdot 49$ & $4.16 \pm 20 \%$ \\
\hline $\begin{array}{l}\text { Venturi shown in } \\
\text { Fig. } 1 \text { (present } \\
\text { work) }\end{array}$ & Water & $\begin{array}{l}1100-\mathrm{O} \mathrm{Al} \\
1018 \text { carbon } \\
\text { steel }\end{array}$ & $\begin{array}{l}0.56-0.62 \\
0.76\end{array}$ & $\begin{array}{r}7-45 \\
13-19\end{array}$ & $36.3-49$ & $\begin{array}{l}4.0_{-16 \%}^{+16 \%} \\
1.06\end{array}$ \\
\hline
\end{tabular}

${ }^{a}$ Unless otherwise indicated.

had been expected from the earlier water tunnel tests of Knapp [2]. The University of Michigan exponents ranged from 1.7 to 4.9 for water and from \pm 1 to 5 for mercury. Knapp's results are included here for comparison (Fig. 9), showing an average velocity exponent value of 6.4. However, Knapp's results are based on pit counts (not on measured weight loss) and on soft aluminum specimens of ogival shape immersed parallel to the flow axis of the large water tunnel at the California Institute of Technology. Test conditions thus differed widely from those of the University of Michigan Venturi. The University of Michigan velocity exponents were calculated from data measured after a stable weight loss rate was obtained and are thus very different from Knapp's pit rate incubation period tests. If our velocity exponent is calculated from data obtained in the early portion of the tests, which was the procedure carried out by Knapp, $n$ is higher. For $1100-O$ aluminum $n \approx 5$ so that the disagreement with Knapp's results is then much reduced. 


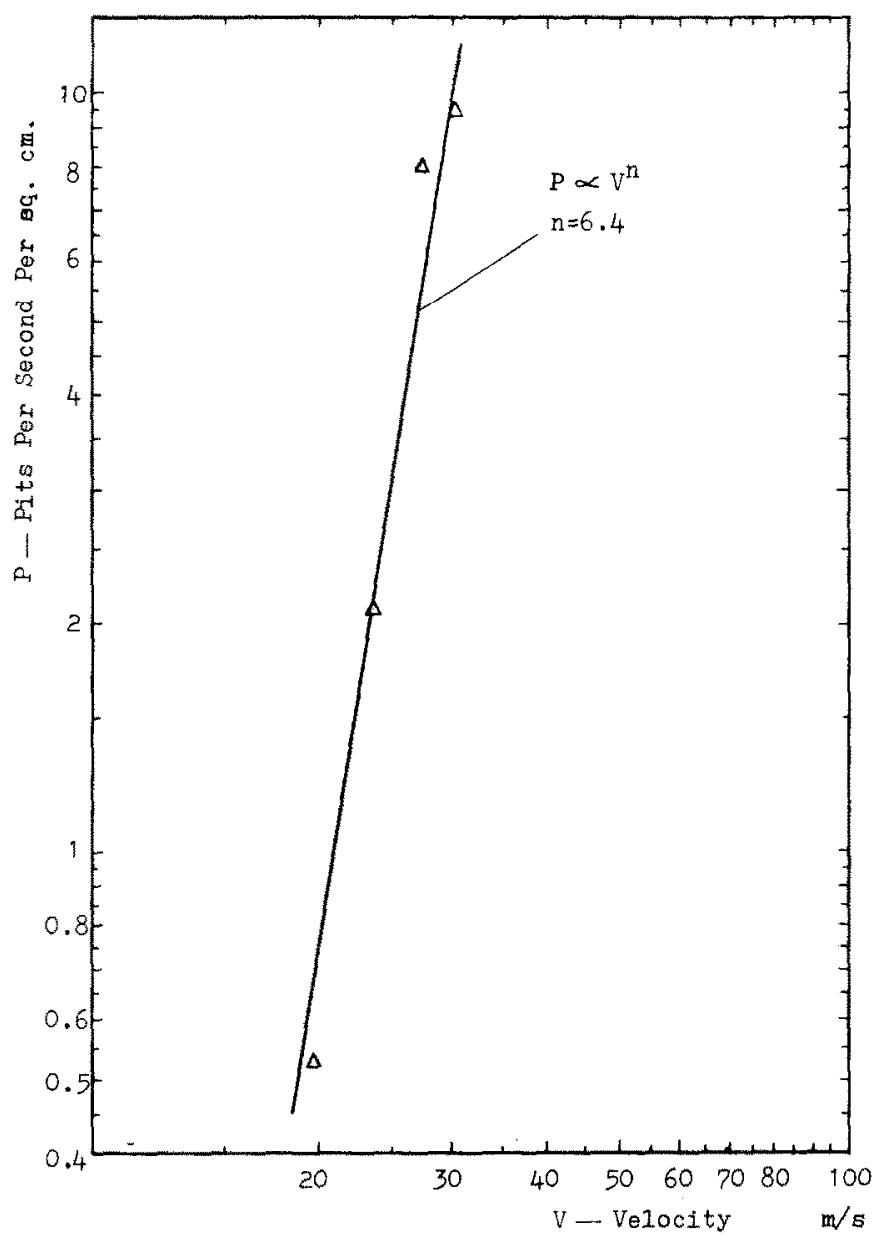

Fig. 9. Effect of velocity on the pit number (material, soft aluminum). (Data from Knapp [2].)

\section{Conclusions}

The following important conclusions can be drawn.

(1) From all the University of Michigan data, the cavitation erosion rate increases with velocity when the cavitation number $\sigma$ is maintained constant. However, the cavitation cloud termination point moves slightly upstream for such conditions.

(2) The velocity exponent $n$ in the relation MDPR $\propto V^{n}$ was about 4 for $1100-0$ aluminum and about 1.1 for 1018 carbon steel in the University of Michigan tests, for well-developed steady state damage conditions. It is higher (about 5) for the incubation period for soft aluminum and is thus reasonably close to Knapp's value of 6 for a similar portion of the test and the same material. 
(3) The probable overall effects of $\sigma$ (based on downstream pressure) on erosion rate at constant velocity for these Venturi tests was deduced (see Fig. 4). In general, MDPR must maximize at intermediate values of $\sigma$ and vanish at either very low or high values of $\sigma$. A simple velocity exponent erosion model is thus not in general tenable.

(4) The erosion rate of 1018 carbon steel was very sensitive to $\sigma$ for the two points tested for fixed velocity; it increased rapidly with $\sigma$ over the range tested (see Fig. 4). For the same values of $\sigma$ there was little erosion change for aluminum.

(5) For all the University of Michigan Venturi investigations to date, with both water and mercury as test liquids, the velocity-damage exponent lies in the range $\pm 1-5$. The velocity ranged from 10 to $49 \mathrm{~m} \mathrm{~s}^{-1}$ for water and from 6 to $20 \mathrm{~m} \mathrm{~s}^{-1}$ for mercury. The negative exponent indicates that some results for mercury [13] show a decrease in damage rate for increased velocity. Similar results for water have been obtained elsewhere (see, for example, ref. 3).

\section{Acknowledgments}

Financial support for this work was provided by Office of Naval Research Contract N00014-78-C-0697, National Science Foundation Grant ENG 75-2315 and also internal University of Michigan Student Employment Program and Work Study funds.

\section{References}

1 F. G. Hammitt, Cavitation and Multiphase Flow Phenomena, McGraw-Hill, New York, 1980 .

2 R. T. Knapp, Recent investigations of cavitation and cavitation damage, Trans. ASME, 77 (1955) $1045-1054$.

3 B. C. Rao and D. V. Chandrasekhara, Size and velocity scale effects on damage in a Venturi, Internal Rep., 1973 (Civil Engineering Department, Bangalore Institute of Technology).

4 A. S. Ramamurthy and P. Bhaskaran, Velocity exponent for erosion and noise due to cavitation, J. Fluids Eng., 101 (March 1979) 69 - 75.

5 J.-g. He, V. Manoukian and G. Heinrich, Erosion of 1018 carbon steel and other materials in a cavitation Venturi, DRDA Rep. UMICH 014456-67-I, August 1980, (Division of Research Development and Administration, University of Michigan, Ann Arbor, MI).

$6 \mathrm{~W}$. W. Williams, Vibratory and Venturi cavitation damage, DRDA Rep. UMICH 014456-81-I, June 1981 (Division of Research Development and Administration, University of Michigan, Ann Arbor, MI).

$7 \mathrm{~W}$. Reecher and D. Olney, Venturi cavitation research, DRDA Rep. UMICH 014456-82-I, June 1981 (Division of Research Development and Administration, University of Michigan, Ann Arbor, MI).

$8 \mathrm{~J} .-\mathrm{g}$. He and C.-D. Hsu, Verifications test of velocity effect upon Venturi cavitation erosion of soft aluminum, DRDA Rep. UMICH 014456-70-I, January 1981 (Division of Research Development and Administration, University of Michigan, Ann Arbor, MI). 
9 T. D. Helmholdt, Venturi cavitation damage run results on $1100-0$ aluminum, DRDA Rep. UMICH 014456-37-I, December 1978 (Division of Research Development and Administration, University of Michigan, Ann Arbor, MI).

10 F. G. Hammitt, J.-g. He, G. Heinrich, C.-D. Hsu, V. Manoukian and B.-H. Sun, Cavitation erosion of ferrous and aluminum alloys in vibratory and Venturi facilities. In R. L. Waid (ed.), Proc. ASME Cavitation and Polyphase Flow Forum, 1981, American Society of Mechanical Engineers, New York, 1981, pp. $24-27$.

11 F. G. Hammitt, T. D. Helmholdt and M. K. De, Erosion of soft aluminum in cavitation Venturi. In R. L. Waid (ed.), Proc. ASME Cuvitation and Polyphase Flow Forum, 1979, American Society of Mechanical Engineers, New York, 1979, pp. 9-12.

12 F. G. Hammitt, Observation on cavitation damage in a flowing system, J. Basic. Eng., 85 (September 1963) $347-359$.

13 F. G. Hammitt, L. L. Barinka, M. J. Robinson, R. D. Pehlke and C. A. Siebert, Initial phases of damage to test specimens in a cavitating Venturi, J. Basic Eng., 87 (1965) $453-464$.

14 F. G. Hammitt, Damage to solids caused by cavitation, Philos. Trans. R. Soc. London, Ser. A, 260 (1966) $245-255$.

15 F. G. Hammitt and D. J. Kempainnen, Cavitation flow past transverse cylinder in Venturi diffuser with water and mercury, Proc. 3rd Conf. on Fluid Mechanics and Fluid Machinery, Budapest, September 1969, Hungarian Academy of Sciences, Budapest, 1969, pp. $255-265$. 